\title{
Quantifying the role of disturbances and speeds on separated bicycle facilities
}

\author{
Silvia Bernardi \\ University of Bologna \\ silvia.bernardi9@unibo.it

\section{Federico Rupi} \\ University of Bologna \\ Federico.rupi@unibo.it
}

\author{
Kevin J. Krizek \\ University of Colorado \\ krizek@colorado.edu
}

\begin{abstract}
As cities aim to spur cycling, a key issue revolves around the location and quality of separated bicycle facilities. However, sometimes owing to impedances, these facilities fail to have the desired overall utility for cyclists. This study focuses on the role of non-stationary disturbances, i.e., the presence of users of other modes. The aim is to quantify the effects and frequencies of disturbances on offstreet bicycle facilities (from other cyclists and pedestrians) and compare them to disturbances (from motorized vehicles) while cycling in mixed traffic. Using three segments in Bologna, Italy, we measured the frequency, type, and speed reduction attributed to different types of disturbances. We analyzed speed and likelihood of events to calculate a weighted average of the cyclists' speed for separated bicycling facilities and on the roadway. For two of the segments, weighted speed reductions were minimal. However, in a third segment-one with considerably more disturbances-speed reductions were considerable: 20 percent for the separated facility and 40 percent for the mixed traffic. When married with cycling use patterns along the facilities, the notable speed reductions point to a possible trade-off cyclists make in choosing between different routes. The results help quantify relationships between cyclists and non-stationary disturbances; they also caution transport officials about possible unintended outcomes for separated bicycle facilities.
\end{abstract}

\section{Article history:}

Received: November 19, 2013

Received in revised form: April

25, 2014

Accepted: April 25, 2014

Available online: March 25, 2015

\section{$1 \quad$ Overview}

As cities worldwide aim to spur more bicycling in cities, a key issue revolves around the nature and design of specific, bicycling-oriented facilities. What design treatments might be necessary to best separate cyclists and pedestrians from traffic? What are associated land use constraints? Available guidelines

Copyright 2015 Silvia Bernardi, Kevin J. Krizek \& Federico Rupi

http://dx.doi.org/10.5198/jtlu.2016.715

ISSN: 1938-7849 | Licensed under the Creative Commons Attribution - Noncommercial License 3.0

The Journal of Transport and Land Use is the official journal of the World Society for Transport and Land Use (WSTLUR) and is published and sponsored by the University of Minnesota Center for Transportation Studies. This paper is also published with sponsorship from WSTLUR and the Institutes of Transportation Studies at the University of California, Davis, and the University of California, Berkeley. 
(e.g., see CROW 2007; NACTO 2012; AASHTO 2012) are usually specific to various countries or contexts and provide differing levels of specificity about the degree to which cycling facilities mix with pedestrians. What remains unknown is detailed knowledge about how pedestrians mix with or impede cycling behavior in different contexts. This research therefore aims to quantify the impact of impedances along different types of cycling facilities, focusing on, but certainly not limited to, the role of pedestrians.

Several research efforts address the effectiveness of dedicated bicycle facilities on outcomes such as cyclist safety, user satisfaction, or other. Using stated-preference (SP) surveys (Abraham et al. 2002; Sener, Eluru, and Bhat 2009; Stinson and Bhat 2005; Krizek and Roland 2005; Tilahun, Levinson, and Krizek 2007), revealed-preference (RP) surveys (Broach, Dill, and Gliebe 2012; Menghini et al. 2010; Hood, Sall, and Charlton 2011), and accident data (Aultman-Hall and Hall 1998; Lusk et al. 2011, 2013; Lusk, Wen, and Zhou 2014), the research base generally suggests that dedicated facilities help spur levels of cycling (Schweizer and Rupi, 2014), provide safety benefits (perceived and real), and advance a more pleasurable cycling experience.

Cyclists consider a variety of factors when evaluating the utility of a route and more specifically, a particular segment of a route. Decisions are often motivated by perceived safety and a desire to maintain ideal cycling speed (i.e., cyclists tend not to want to be slowed by various obstructions). Safety and speed are influenced by the geometric design of the facilities (turning radii, slope, lane width) and functional features (proximity to cars, speed of adjacent cars, proximity of car parking stalls, presence of disturbances on the facility). But key dimensions that have received less attention in the design and research about bicycle facilities revolve around disturbances; specific obstacles in the facility that affect user satisfaction.

Disturbances may be stationary (e.g., intersections, utility poles, bollards) or non-stationary (e.g., other cyclists or pedestrians).

For example, intersections that punctuate bicycle facilities have shown to be particularly vexing; the body of literature examining intersections along off-street paths is burgeoning (Phillips et al. 2011; Schepers et al. 2011; Sorton and Walsh 1994; Strauss and Miranda-Moreno 2013). In the path/route choice literature, using both SP- and RP-based studies Broach, Dill, and Gliebe (2012) and Sener, Eluru, and Bhat (2009) found that route utility was reduced by high-traffic crossings, stop signs, and traffic signals. Although the delay of these intersections can vary and be modified to favor cyclists, depending on the traffic-control devices used (signals or stop signs), more intersections than fewer are often perceived as a nuisance and impedance.

A different type of disturbance is non-stationary in nature-another cyclist or a user of another mode. Sometimes, the utility of a separated bicycle facility may be undetermined because of the intended or unintended need to mix with other modes. Pedestrians are a prime example of this. Little research, however, has focused on the extent to which pedestrians mixing with cyclists decrease the speed and therefore lessen the utility.

The most relevant literature we are aware of in this respect refers to "pedestrian hindrances." For example, knowing volumes and speeds of pedestrians and cyclists, Botma (1995) initially proposed a model to evaluate the number of passing and meeting events on off-street facilities. This work was later adopted and applied to different contexts (Allen et al 1998; Virkler et al. 1998; Green, Hummer, and Rouphail 2003; Highway Capacity Manual 2010) to demonstrate how hindrances affect functional characteristics of bicycle facilities. The main contribution of these studies was the determination of a level of service for shared off-street facilities based on the number of passing and meeting events. This work, however, left issues unanswered, such as the specific impact of hindrances on users' speed. Also, Botma's methodology supposes a normal distribution of bicycle speeds and fails to consider alternatives such as mixing with traffic.

We aim to fill this gap in the literature by systematically analyzing three transportation segments in 
Bologna, Italy. We considered two different environments: off-street bicycle facilities and mixed traffic conditions in the roadway. By definition, off-street facilities include both separated bicycle facilities (exclusive to cyclists—called cycleways—or shared with pedestrians) and cycle tracks (i.e., bicycle-exclusive paths) (European Economic and Social Committee 2012).

We focus here exclusively on non-stationary disturbances to cyclists: pedestrians and bicyclists for the off-street environment and motorized vehicles for the roadway environment. We compared cycling travel speeds in each environment to quantify speed reductions, largely types and amounts of nonstationary disturbances.

Our results contribute to the literature by quantifying cyclist speed reductions from pedestrians (on off-street facilities) and motorized traffic (on the roadway). This work has direct implications for developing decay curves that relate travel speed on cycling facilities with pedestrian volumes; such decay curves prove useful for the future planning of dedicated facilities in urban areas. We describe the context of our research and the specifics of the three segments. The following section details our data collection process and results. The conclusions discuss implications and future research needs.

\section{The specific context of separated cycling facilities}

Our research focuses on disturbances that are situated in a particular cultural context. It is therefore helpful to describe each as they apply to our study — being situated in Bologna — and some peculiarities relating to bicycle facilities. Structural and functional aspects of cycling facilities in Italy are regulated by the Codice della Strada, along with the Decreto Ministeriale number 557 from 1999, "Regolamento recante norme per la definizione delle caratteristiche tecniche delle piste ciclabili." These regulations offer guidelines to plan and design cycling facilities, stating as their aim, "the achievement of a proper level of safety and environmental sustainability" (Decreto Ministeriale number 557 of 1999, Article 1). Different designs for off-street facilities described by the Italian guidelines are shown in Figure 1. These guidelines, similar to the situation in many countries, prescribe various types of bicycle facilities for different types of traffic situations. There is wide variation in the types of facilities and the manner in which they separate cyclists from cars.

Note at least three factors run in the face of these guidelines. The first is that it is not uncommon for a cycling facility to be constructed with design treatments misapplied in a given context; alternatively, specific standards might be waived or ignored. Second, contextual factors (most often lack of space) affect the overall quality of specific design elements. For example, in some instances, an "off-street bicycle facility" is comprised of a raised treatment (e.g., a curb with accompanying bricks) on one side of the street to separate the cyclist from cars. The other side of the cycling lane, however, might merely be a painted stripe to separate cyclists from pedestrians. This leads to a third issue: Even when a facility is designed and rules for its use are specified, regulations are mere suggestions. When space for pedestrians is provided in adjacent space or banned from the cycling facility altogether, it is not uncommon for pedestrians to encroach on the cycling facility. In cases of high pedestrian flows, they merely "spill over" into the cyclist facility. This is commonplace not only in Bologna, but also in many cities throughout Europe where it is difficult to find space for non-motorized travel in extremely space-constrained situations. 
a)

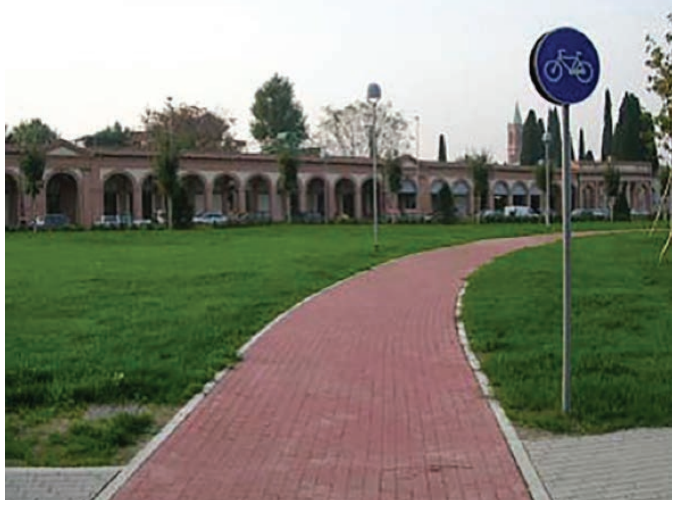

c)

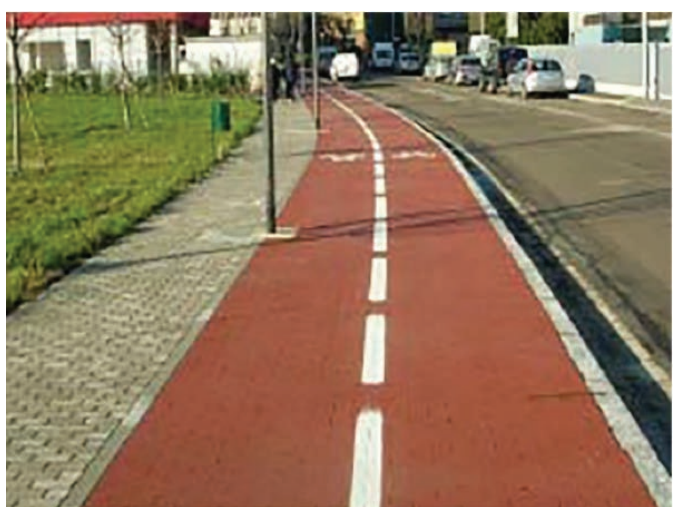

b)

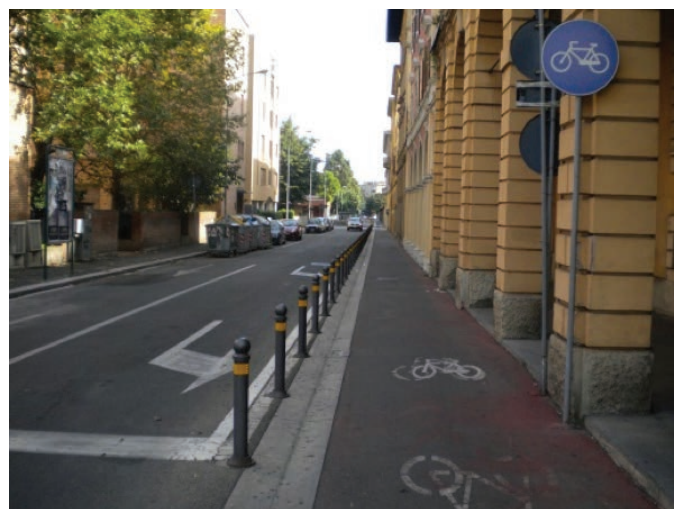

d)

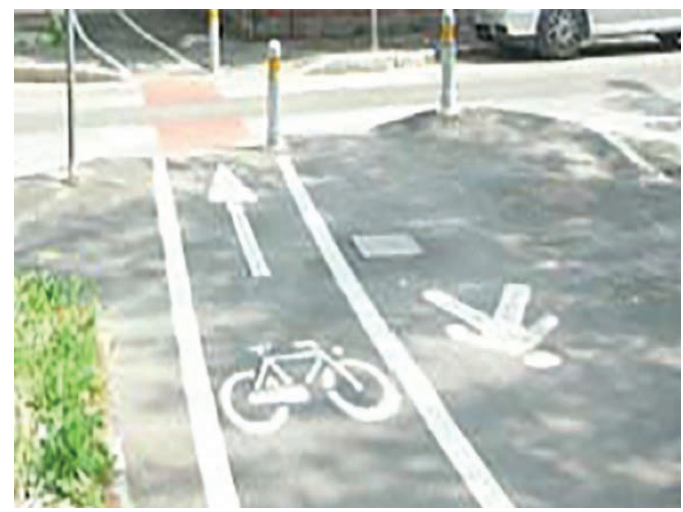

Figure 1: Some examples of the off-street facility typologies in Italy, as categorized in the Italian regulation: a) separated path non-adjoining the roadway; b) separated path, separation obtained by a non-continuous barrier; c) cycle track, obtained from the sidewalk, separating pedestrian and bicycle areas with different pavements; d) cycle track, obtained from the sidewalk, separating pedestrian and bicycle areas by painted markings.

\section{Research approach}

\subsection{Selection of segments studied and their characteristics}

Our central objective was to quantify how different types of disturbances affect cyclist travel speed; we chose three segments of Bologna's cycling network to do so (Figure 2) ${ }^{1}$. Our primary concern was on the interplay between pedestrians and cyclists in off-street bicycle facilities-but we aimed to do so, in part, relative to disturbances caused by motorized vehicles (cars, buses/trucks, motorcyclists) in mixed traffic. We therefore chose to study segments with: (a) an off-street bicycle facility adjacent to the roadway, (b) varying levels of pedestrian use around them, and (c) varying traffic volumes on the roadway. To the extent possible, we chose segments away from key intersections, allowing us to better focus on primary characteristics of segments vis-a-vis cyclists travel behavior. Similarly, we aimed to keep speeds of vehicular travel constant as best as possible. The segments were defined to be 20 meters long, and the location of each is approximately 2 kilometers from the center of Bologna. Characteristics of each segment are described below with locations shown in Figure 2. Summary characteristics are presented in Table 1.

\footnotetext{
${ }^{1}$ We employ the following nomenclature throughout this manuscript to improve clarity. Segments are the three areas studied; each segment is approximately 20 meters long. These segments contain an off-street bicycle facility (that is separated from traffic via a physical means — raised curb, parked cars or median), and an adjacent travel lane where cyclists can mix with motorized traffic, i.e., the roadway. Therefore, each segment has two different types of environment.
} 


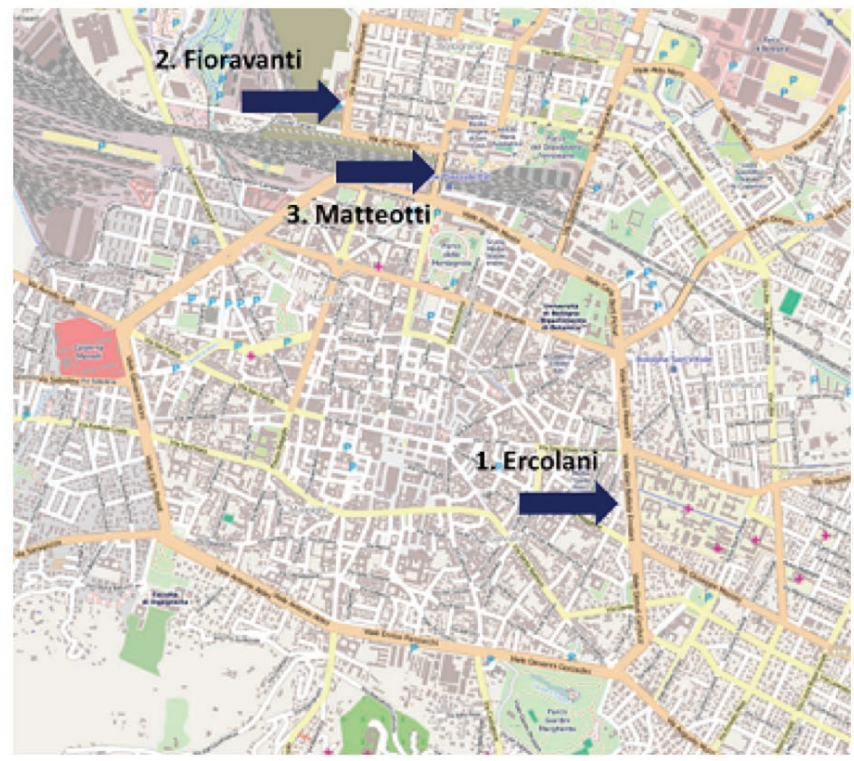

Figure 2: Map of Bologna and location of the three segments

Table 1: Features of the three segments examined

\begin{tabular}{|l|l|c|c|l|c|c|}
\hline Segments & $\begin{array}{c}\text { Type of off- } \\
\text { street bicycle } \\
\text { facility }\end{array}$ & $\begin{array}{c}\text { Width of the } \\
\text { bicycle area } \\
(\mathbf{m})\end{array}$ & $\begin{array}{c}\text { Width of the } \\
\text { pedestrian area } \\
\mathbf{( m )}\end{array}$ & $\begin{array}{c}\text { Pedestrian } \\
\text { volumes }\end{array}$ & $\begin{array}{c}\text { Posted speed } \\
\text { limit of adjacent } \\
\text { roadway } \mathbf{( k m} / \mathbf{h})\end{array}$ & $\begin{array}{c}\text { Peak bus volumes } \\
\text { on adjacent road- } \\
\text { way /hour }\end{array}$ \\
\hline (1) Ercolani & $\begin{array}{l}\text { Exclusive sepa- } \\
\text { rated facility }\end{array}$ & 1.80 & - & Low & 50 & 40 \\
\hline (2) Fioravanti & $\begin{array}{l}\text { Cycle track on } \\
\text { pavement }\end{array}$ & 2.10 & 1.90 & Modest & 50 & 5 \\
\hline (3) Matteotti & $\begin{array}{l}\text { Cycle track on } \\
\text { pavement }\end{array}$ & 1.90 & 1.50 & High & 50 & 55 \\
\hline
\end{tabular}

(1) Ercolani (Figure 3) is along the first ring road of the city. It includes two carriageways with 50 kilometer per hour traffic that is divided by a median strip. Both sides of the northbound and southbound carriageways carry buses: 40 per hour going southbound during peak times; and 20 per hour going northbound. The off-street bicycle facility in this section is part of a separated facility with bidirectional lanes, reserved only for cyclists ${ }^{2}$.

\footnotetext{
${ }^{2}$ The red-circled sign with the pedestrian indicates pedestrians are technically prohibited from the facility.
} 


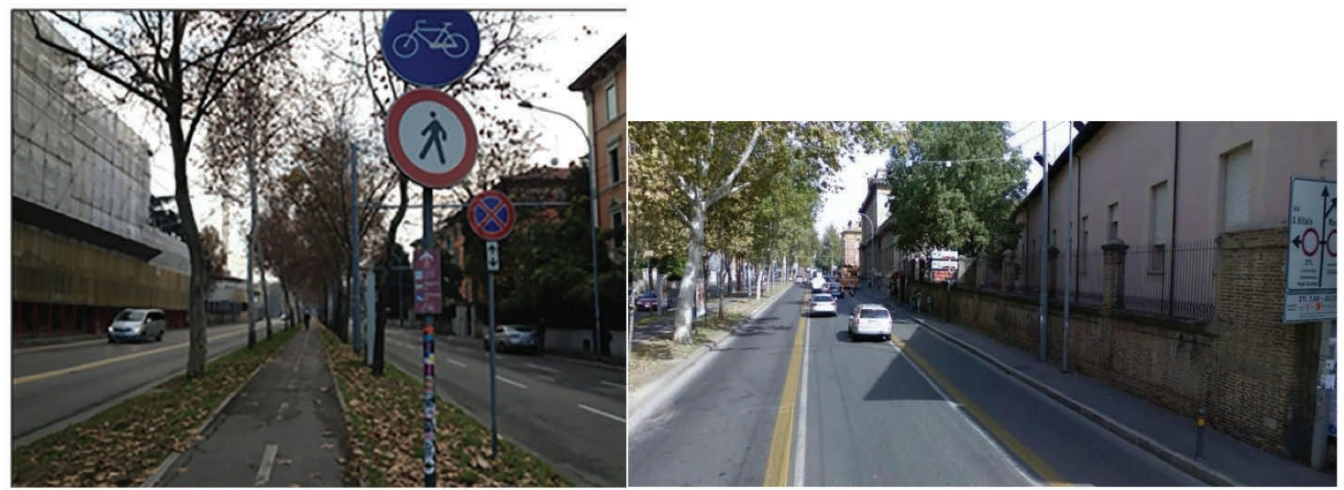

Figure 3: The off-street facility and roadway layout in Segment 1

(2) Fioravanti (Figure 4) is along a one-way street that heads toward the city center (southbound). Bus traffic is considerably less than in Segment 1 ( 5 per hour), but lateral parking is permitted on both sides of the roadway. The off-street bicycle facility in this section is bidirectional and separated from a pedestrian zone by a painted stripe. Pedestrian volumes are modest.
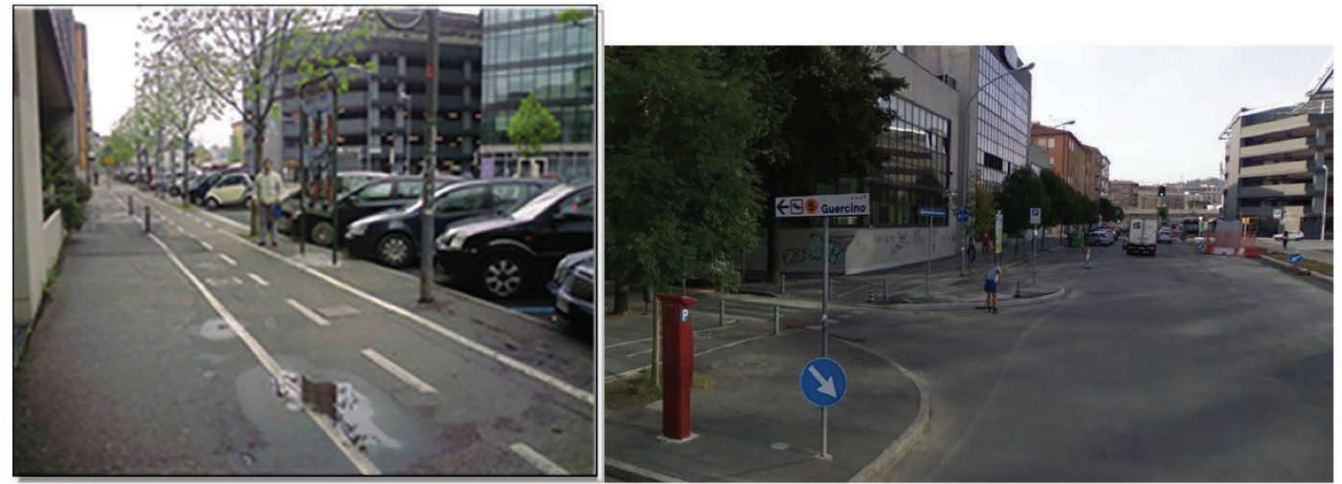

Figure 4: The off-street facility and roadway layout in Segment 2

(3) Matteotti (Figure 5) is adjacent to a four-lane road close to the central train station; three lanes head southbound, and one is reserved for northbound traffic. The character of the off-street bicycle facility in this section is similar to that in Segment 2. Being close to the central train station, bicycle, pedestrian, and motorized volumes are high. On average, bus volumes are between 50 and 60 per hour, using all three southbound lanes. 


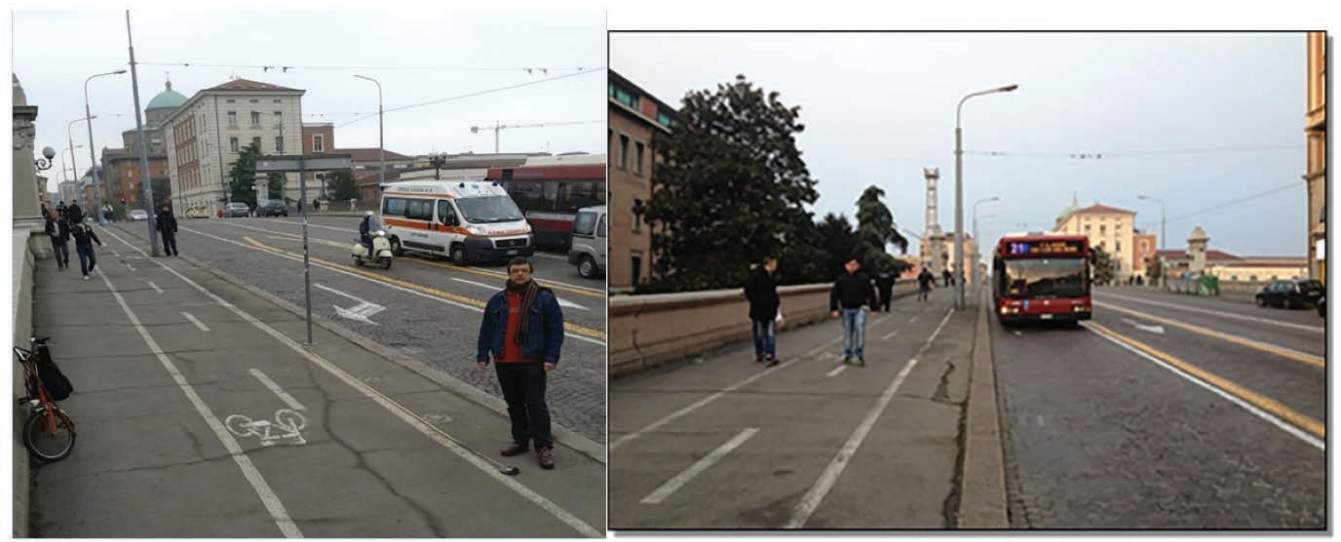

Figure 5: The off-street facility and roadway layout in Segment 3

\subsection{Data collection}

For each of the three segments, we studied cyclist travel on the off-street bicycle facility and on the immediately adjacent roadway (for a total of six environments). We chose seven working days (from 8:30 a.m. until 10:30 a.m.) in April 2012 to be best representative of general cycling conditions. We collected data in two different phases. The first phase counted the number of cyclists on each of the six different environments and timed how long each cyclist took to travel the 20-meter stretch. We tallied cyclists in all directions according to the environment they were cycling in (off-street versus roadway). This data provided us with baseline information about speed and also pointed to general patterns of use across the different facilities.

In the second phase we administered our own experiments to collect data relating to disturbances and speed. One researcher cycled in each environment approximately 100 times. Employing the typology presented in Table 2, he used his own judgment to record all types of disturbance he encountered. For example, pedestrians encroaching onto the off-street bicycle facility were a disturbance; in the mixed traffic, cars or buses that forced him to share a lane or otherwise affected his travel were a disturbance. The researcher was asked to conform to typical cycling behavior, and to keep it consistent (e.g., when to pass other cyclists). Furthermore, he was encouraged to apply consistency in how each type of disturbance was classified. The other researcher timed the cyclist on the 20 -meter stretch. The research team did this approximately 100 times for each environment, totaling almost 600 coupled measures.

Table 2: Classes of disturbances considered

\begin{tabular}{|l|l|}
\hline \multicolumn{1}{|c|}{ Off-Street Bicycle Facility } & \multicolumn{1}{c|}{ Roadway } \\
\hline No pedestrians, bikes in same direction & No disturbances or two-wheeled vehicles \\
\hline No pedestrians, bikes in opposite direction & 1 car or more \\
\hline $1-3$ pedestrians & 1 bus or more \\
\hline 4 pedestrians or more & Heavy vehicles \\
\hline
\end{tabular}




\section{$4 \quad$ Analysis and results}

\subsection{Speed and use attributes}

We first aimed to better understand baseline measures for each of the three environments and the relative characteristics. Segment 3 had the highest volume of cyclists, recording an average of 850 cyclists for the two-hour period; Segment 1 averaged 480 cyclists and Segment 2 had 240. These volumes are consistent with the intensity of land uses and activities around each segment (e.g., Segment 1 is adjacent to the central station and along a primary corridor headed into town; Segment 2 is in a more peripheral location and on a minor road). Using data collected from this phase, we calculated average speeds for each environment; summary results are shown in Table 3. Average cycling speeds varied between 14.6 and 22 kilometers per hour, which generally agree with the values reported in Allen et al. (1998). Most studies with which we are familiar found bicycle speeds to be normally distributed; this varied by facility in our data and distributions for each are shown in Figure 6. A significance t-test was performed for the two speed samples, comparing off-street facility and mixed traffic data, and results revealed a statistically significant difference between the two samples for all the three segments.

Across all segments, average cyclist speed was higher in the mixed traffic facility than on the offstreet bicycle facility. Overall, cyclists' speeds were highest in Segment 1 (18.9 kilometers per hour on the off-street bicycle facility and 22 kilometers per hour in mixed traffic), largely owing to pedestrians being technically forbidden in the off-street facility and cyclists often using the dedicated bus lanes in the roadway.

Figure 7 shows the proportion of cyclists using the different environments. Segment 2 had the highest percentage of cyclists using the off-street facility ( 73 percent), followed by 58 percent in Segment 1. In contrast, less than half of the cyclists ( 47 percent) used the off-street facility in Segment 3. Even in Segment 1, where the off-street facility is not shared with other users, 42 percent of the cyclists chose to mix with traffic. Several factors contribute to these patterns and explaining them is clearly beyond the scope of our immediate study. Common sense suggests that variations and revealed preferences have to do with the width of the adjacent corridor for pedestrians (which lead to disturbances); other matters relate to discontinuities of the off-street facility farther upstream (or downstream). Still other factors may be due to cyclists' desire to link origins and destinations along the corridor; the specific facility might be out of the way of their needed route. But some of the variation is also influenced by intensity of the non-stationary disturbances (particularly pedestrians) in affecting speed along the routes. We now turn to quantifying the extent of these non-stationary disturbances in terms of decreased speed.

Table 3: Cyclists' volumes and average speeds for the three segments

\begin{tabular}{|c|c|l|c|c|}
\hline \multirow{2}{*}{ Segments } & $\begin{array}{c}\text { Average \# of cyclists } \\
\text { measured in 2 hours }\end{array}$ & \multicolumn{1}{|c|}{ Statistic } & $\begin{array}{c}\text { Off-street bicycle } \\
\text { facility }\end{array}$ & Roadway \\
\hline \multirow{3}{*}{ (1) Ercolani } & \multirow{2}{*}{480} & Mean speed $(\mathrm{km} / \mathrm{h})$ & 18.90 & 22.00 \\
\cline { 3 - 5 } & & Standard deviation $(\mathrm{km} / \mathrm{h})$ & 3.16 & 5.08 \\
\cline { 3 - 5 } & & Coeff. of Variation & 0.168 & 0.231 \\
\hline \multirow{3}{*}{ (2) Fioravanti } & \multirow{2}{*}{240} & Mean Speed $(\mathrm{km} / \mathrm{h})$ & 14.60 & 16.8 \\
\cline { 3 - 5 } & & Standard deviation $(\mathrm{km} / \mathrm{h})$ & 3.12 & 4.24 \\
\cline { 3 - 5 } & & Coeff. of Variation & 0.213 & 0.252 \\
\hline \multirow{3}{*}{ (3) Matteotti } & \multirow{2}{*}{850} & Mean Speed $(\mathrm{km} / \mathrm{h})$ & 16.00 & 17.00 \\
\cline { 3 - 5 } & & Standard deviation $(\mathrm{km} / \mathrm{h})$ & 2.97 & 4.39 \\
\cline { 3 - 5 } & & Coeff. of Variation & 0.186 & 0.259 \\
\hline
\end{tabular}


Segment 1 - Ercolani

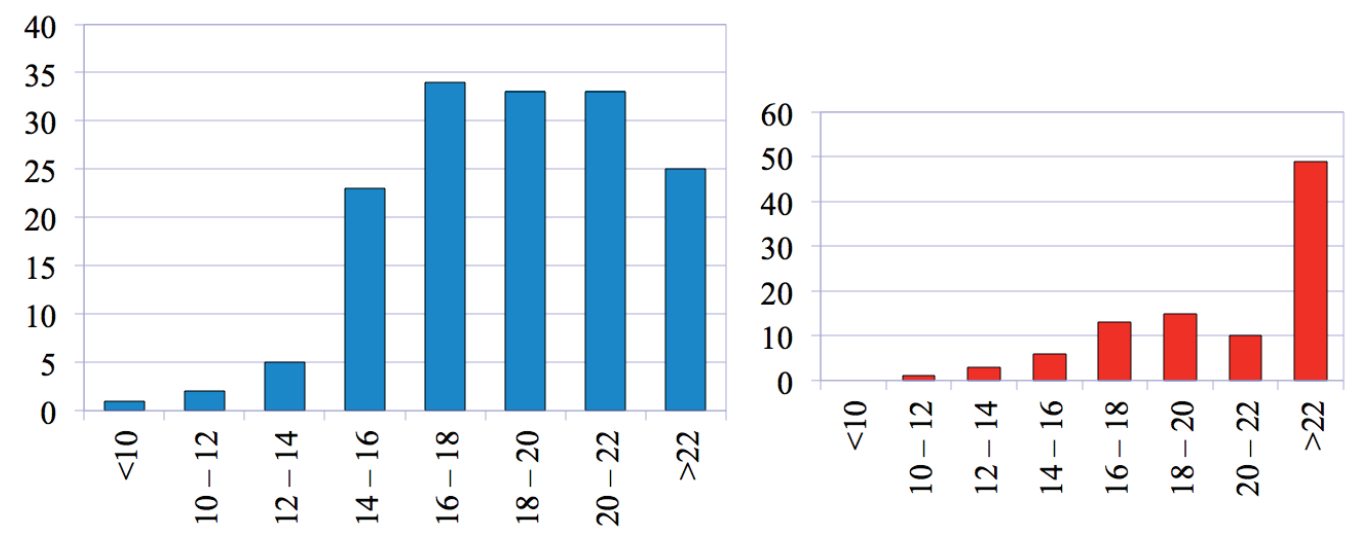

Segment 2 - Fioravanti
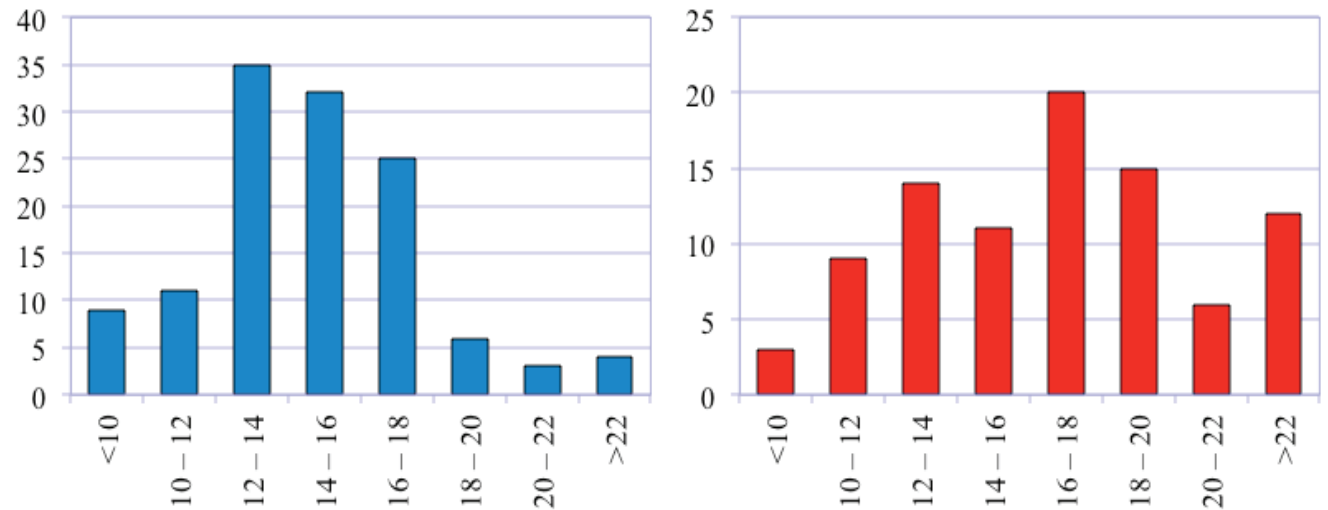

Segment 3 - Matteotti
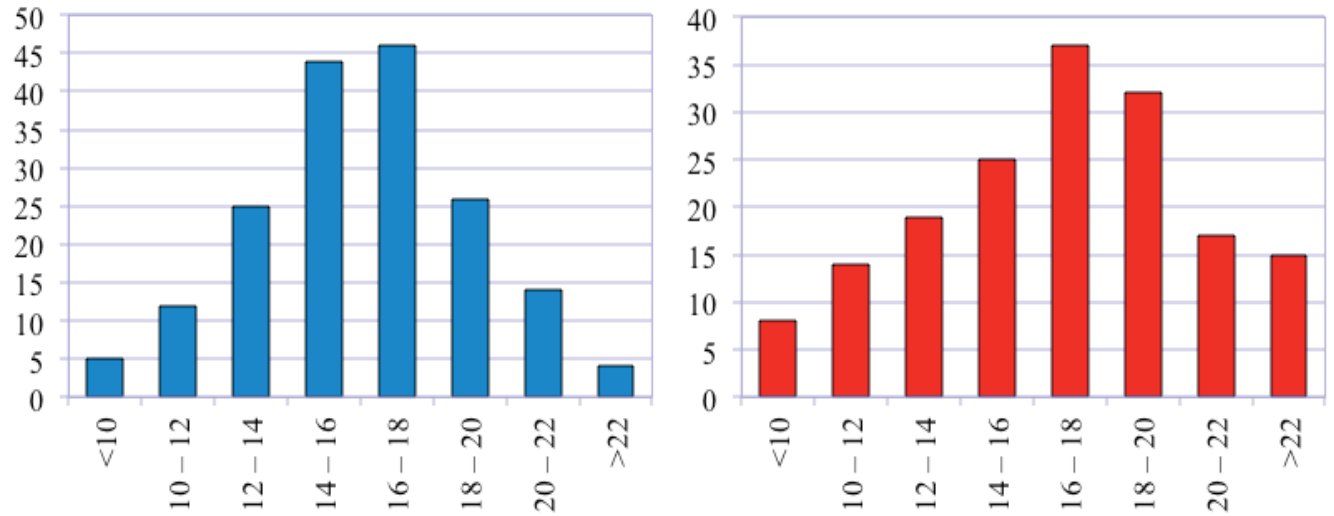

Figure 6: Cyclists' travel speed distributions. On the horizontal axes, speed values are divided in ranges; the bars represent the frequency of speeds. The results for separated bicycle facilities are in blue, and the results in red are those for the roadway. 


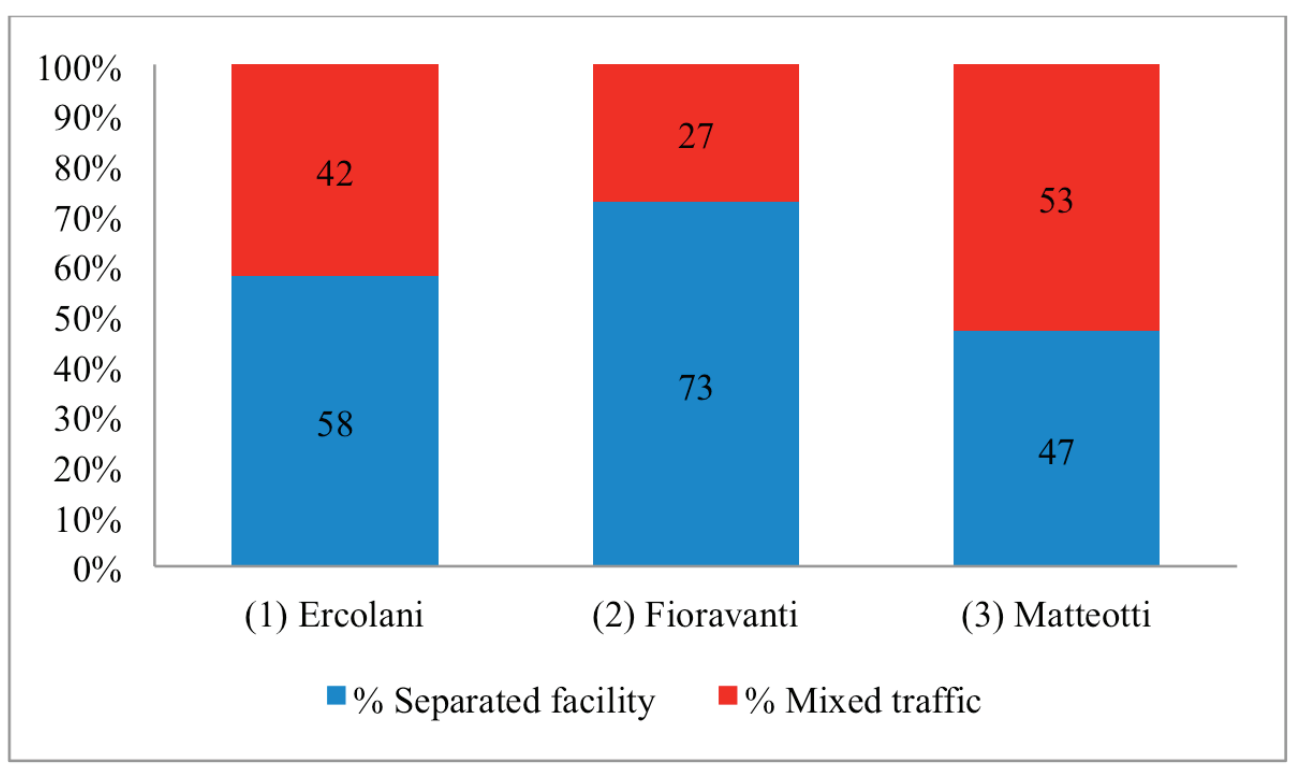

Figure 7: Cyclist use by facility

\subsection{Disturbance analysis}

For each of the approximate 600 coupled observations, we calculated average speeds and examined them relative to the type of disturbance. For each recorded disturbance, we calculated the speed reduction compared to free-flow (undisturbed) travel conditions. We also tallied the frequency of the different types of disturbances, reflected as a proportion of measurements where a disturbance was recorded. Finally, we calculated the average speed weighted by the frequency of each disturbance for both the offstreet bicycle facility and the roadway. Results are shown in Tables 4 and 5, by segment.

Average travel speeds reflect the probability of each type of disturbance. The bottom row in the tables shows the frequency of measurements where at least one disturbance was registered-as a complement to the percentage of measurements where no disturbances were registered. The cyclist-researcher experienced a disturbance approximately half the time. And when the cyclist-researcher experienced no disturbances, his speeds generally agreed with the speeds recorded from phase one of the data collection. For Segments 1 and 3, disturbances were more frequent on the off-street bicycle facilities (54 percent and 90 percent of the time) than on the roadway ( 45 percent and 58 percent, respectively). The frequency of disturbances was more balanced across the facilities for Segment 2 (58 percent for separated and 62 percent for mixed).

The frequency by type of disturbance varied. Pedestrians were most common for the off-street facilities in Segments 2 and 3; for Segment 3, a cyclist would encounter a pedestrian in 90 percent of the observances. Cyclists in the opposite direction were most common in Segment 1. For the roadway, cars were clearly the most common disturbance ( 24 percent, 57 percent, and 47 percent of observances).

In each of the off-street facilities, pedestrians had the largest impact on cyclists' travel speed, affecting a 10-27 percent reduction. Other cyclists were second, slowing speeds by 5 percent, on average. The speed reduction was felt most acutely in Segment 3-owing to a variety of factors-but overall pedestrian volumes were clearly one of them.

In mixed traffic, we noticed speed reductions from cars and trucks; disturbances from motorcycles were negligible. In Segment 1, buses led to speed reductions of 25 percent; in Segment 3, cars and buses 
led to speed reductions of 32 percent and 37 percent, respectively. The largest impact was associated with heavy vehicles, a 63-percent speed reduction. In general, cars, buses, and heavy vehicles, have the greatest impact on reducing cyclist travel speed, with pedestrians much less likely to have an impact.

Furthermore, we considered weighted average- jointly analyzing the average speed reduction weighted by frequency of disturbance. For Segments 1 and 2, weighted speed reductions are relatively minor, ranging between 2 percent and 14 percent. The weighted speed reductions we calculated in Segment 3 were considerable: 20 percent for the off-street facility and 40 percent for the mixed traffic. This segment is rich in disturbances and has notable speed reductions. Our analysis suggests cyclists might be making route choice trade-offs that are influenced by two factors: (1) frequent pedestrian disturbances on the off-street facility that produce moderate speed reductions, and (2) relatively fewer disturbances on the roadway that have more severe speed reductions. Most cyclists prefer to travel in the mixed traffic - though robustly explaining this phenomena is beyond the scope of this data collection exercise.

Such factors suggest that the attractiveness of a bicycle facility is affected by jointly considering the frequency of disturbances and their effects. This joint calculus is a contributing factor in a cyclist's decision to use an off-street facility versus the roadway. In other words, even if cyclists know that encountering a heavy vehicle might present a safety hazard, at least on segments we studied, the event could be perceived to be rare enough for them to choose the mixed-traffic condition.

Table 4: Cycling speeds by type of disturbance (off-street bicycle facilities)

\begin{tabular}{|c|c|c|c|c|c|c|}
\hline \multirow[b]{2}{*}{ Disturbance type } & \multicolumn{2}{|c|}{ (1) Ercolani } & \multicolumn{2}{|c|}{ (2) Fioravanti } & \multicolumn{2}{|c|}{ (3) Matteotti } \\
\hline & $\begin{array}{l}\text { Average Travel } \\
\text { Speed }(\mathbf{k m} / \mathbf{h})\end{array}$ & \% Reduction & \begin{tabular}{|l} 
Average Travel \\
Speed $(\mathbf{k m} / \mathbf{h})$
\end{tabular} & \% Reduction & $\begin{array}{c}\text { Average Travel } \\
\text { Speed }(\mathbf{k m} / \mathbf{h})\end{array}$ & $\%$ Reduction \\
\hline No disturbance & 16.7 & - & 15.2 & - & 15.6 & - \\
\hline$\%$ of events & $45.9 \%$ & & $41.9 \%$ & & $9.6 \%$ & \\
\hline Bikes same direction & 16.0 & $4.2 \%$ & 14.1 & $6.8 \%$ & 15.5 & $0.14 \%$ \\
\hline$\%$ of events & $6.6 \%$ & & $13.3 \%$ & & $4.8 \%$ & \\
\hline Bikes opp. direction & 16.2 & $3.1 \%$ & 14.4 & $5.0 \%$ & 14.1 & $9.0 \%$ \\
\hline$\%$ of events & $29.5 \%$ & & $10.7 \%$ & & $1.2 \%$ & \\
\hline $1-3$ pedestrians & 14.5 & $13.1 \%$ & 13.5 & $10.8 \%$ & 12.3 & $20.9 \%$ \\
\hline$\%$ of events & $13.1 \%$ & & $33.3 \%$ & & $84.3 \%$ & \\
\hline 4 pedestrians or more & n.a. & n.a. & 13.5 & $11.1 \%$ & 11.3 & $27.2 \%$ \\
\hline$\%$ of events & $0.0 \%$ & & $1.3 \%$ & & $18.1 \%$ & \\
\hline \multicolumn{7}{|c|}{ Average speed, weighted by disturbance } \\
\hline & 15.6 & $6.4 \%$ & 13.9 & $8.8 \%$ & 12.5 & $19.6 \%$ \\
\hline$\%$ of events & $54.1 \%$ & & $58.1 \%$ & & $90.4 \%$ & \\
\hline
\end{tabular}


Table 5: Cycling speeds by type of disturbance (roadway)

\begin{tabular}{|c|c|c|c|c|c|c|}
\hline \multirow[b]{2}{*}{ Disturbance type } & \multicolumn{2}{|c|}{ (1) Ercolani } & \multicolumn{2}{|c|}{ (2) Fioravanti } & \multicolumn{2}{|c|}{ (3) Matteotti } \\
\hline & $\begin{array}{l}\text { Average Travel } \\
\text { Speed }(\mathbf{k m} / \mathbf{h})\end{array}$ & \% Reduction & $\begin{array}{l}\text { Average Travel } \\
\text { Speed }(\mathbf{k m} / \mathbf{h})\end{array}$ & \% Reduction & $\begin{array}{l}\text { Average Travel } \\
\text { Speed }(\mathbf{k m} / \mathbf{h})\end{array}$ & $\%$ Reduction \\
\hline No disturbance & 18.6 & - & 17.0 & - & 17.7 & - \\
\hline$\%$ of events & $55.2 \%$ & & $37.5 \%$ & & $42.1 \%$ & \\
\hline Two-wheeled vehicle & 18.4 & $1.1 \%$ & 17.0 & $0.26 \%$ & 17.3 & $2.2 \%$ \\
\hline$\%$ of events & $10.3 \%$ & & $3,1 \%$ & & $5,3 \%$ & \\
\hline 1 car or more & 17.0 & $9.0 \%$ & 16.8 & $1.15 \%$ & 12.0 & $31.7 \%$ \\
\hline$\%$ of events & $24.1 \%$ & & $56.3 \%$ & & $47.4 \%$ & \\
\hline 1 bus or more & 13.8 & $25.8 \%$ & n.a & n.a & 11.1 & $37.2 \%$ \\
\hline$\%$ of events & $10.3 \%$ & & $0.0 \%$ & & $21.1 \%$ & \\
\hline Heavy vehicles & n.a & n.a & 14.9 & $12.3 \%$ & 6.6 & $62.9 \%$ \\
\hline$\%$ of events & $0.0 \%$ & & $3.1 \%$ & & $2.6 \%$ & \\
\hline \multicolumn{7}{|c|}{ Average speed, weighted by disturbance } \\
\hline & 16.0 & $14.1 \%$ & 16.7 & $1.8 \%$ & 10.53 & $40.5 \%$ \\
\hline$\%$ of events & $44.8 \%$ & & $62.5 \%$ & & $57.9 \%$ & \\
\hline
\end{tabular}

\section{$5 \quad$ Implications and future research}

Aiming to spur non-motorized travel, transport officials in cities are often challenged by finding available space in travel corridors for dedicated cycling facilities. This work informs these matters in several respects and also provides a springboard to spur future research on the issue. We employed a data collection approach to quantify the speed effects of non-stationary disturbances - disturbances that often influence cyclists' route choice decisions. Relying on speed as just one of several performance measures, we measured the joint effects of disturbance frequency and disturbance impact.

We learned that motorized disturbances (particularly heavy vehicles) have the strongest impact on lowering cyclists' travel speed. However, these specific disturbances proved to be relatively infrequent relative to those encountered on off-street bicycle facilities (where pedestrians are more plentiful and contribute to slowing the speed of cyclists). To our knowledge, this is the first data collection effort and analysis to point to this trade-off. Furthermore, failing proper separation between users, we learned that the presence of pedestrians can reduce cyclists speed by up to 30 percent.

Myriad factors influence a cyclist's route choice, particularly the decision to use an off-street bicycle facility or ride in traffic. The probability of disturbances and their impact on travel speed are just two of them. Our results suggest that design elements of these facilities can play a role in affecting the frequency, type, and severity of disturbances. However, it is necessary for future work to better isolate this element (e.g., better projecting how wide sidewalks need to be given pedestrian volumes to avoid disturbing the bicycle facility). For example, Segment 2 had excess space for pedestrian travel and therefore little speed reductions from pedestrians; cyclists can avert pedestrians without significantly reducing their speed, and, evidently pedestrian safety results are also enhanced. Furthermore, wider cycle-tracks (when warranted) benefit cyclist-cyclist interactions because it is easier to pass each other going in the same direction.

Our data collection effort represents a univariate population, which is an oversimplification. Different types of cyclists prefer different environments (Larsen and El-Geneidy 2011; Sener, Eluru, and Bhat 
2009; Wilkinson et al. 1994). This type of investigation could benefit from more robustly accounting for demographic, attitudinal, or other behavioral data, which was unfortunately unavailable for this effort. Furthermore, the type of detailed GPS data that is now being employed in other bicycle research applications (Broach, Dill, and Gliebe 2012; Hood, Sall, and Charlton 2011; Menghini et al. 2011) could be adapted to focus specifically on issues we studied here. GPS technology could then be used to focus on the role of trip type and broader route choice characteristics.

A subsequent step would be to integrate these results into a bicycle route choice model where frequency of disturbance and its magnitude represent various attributes of the utility. In the current state of the research, the most advanced approach merely considers the proportion of the facility that is separated for bicycling (Broach, Dill, and Gliebe 2012; Hood, Sall, and Charlton 2011; Menghini et al. 2010). Finally, this research documents the frequency and quantifies the intensity of disturbances on speed. As future research on this matter evolves, cities would benefit from learning about various thresholds of pedestrian volume and corresponding cycling speed impacts. This work lays the foundation to create a decay curve, which could be used to predict travel speed vis-à-vis pedestrian volumes (similar to how speed decay curves of vehicle flow are used to determine the level of service of infrastructures). Planners would then be able to more robustly estimate cyclist speeds - and levels of service-for different pedestrian volumes.

\section{Conclusions}

When off-street bicycle facilities are poorly designed or placed in less than optimum locations (such as in Segment 3), their intended use is less than anticipated. By analyzing the speed reductions from different types of disturbances, we found that frequency of disturbance might weigh more heavily than the intensity of the disturbance. Furthermore, encountering pedestrians along an off-street bicycle facility lowers average speeds by as much as 30 percent, especially in situations where the bicycle facility fails to conform to minimum standards. In mixed traffic, the presence of motorized vehicles can produce even more severe speed reductions (i.e., in the case of heavy vehicles), but these interactions proved to be less frequent.

Most policy officials know they need to heed caution when prescribing off-street bicycle facilities adjacent to areas with high pedestrian activity. An outstanding question is how many pedestrians present a problem and the corresponding speed reductions. For researchers, this work helps spearhead more robust investigations to establish, for example, speed decay curves based on pedestrian volumes. For practitioners, our results draw attention to the need for physically separating pedestrians from cyclists in facility design. Or, where the context suggests less than optimum conditions for an off-street facility, it helps quantify when it might be more convenient to better accommodate bicycle travel in mixed-traffic conditions. 


\section{References}

AASHTO. 2012. Guide for the Development of Bicycle Facilities. Washington, DC: American Association of State Highway and Transportation Officials.

Abraham, J., S. McMillan, A. Brownlee, and J. D. Hunt. 2002. Investigation of cycling sensitivities. Presented at the 81st Annual Meeting of the Transportation Research Board, January 13-17, Washington, D.C.

Allen, D. P., N. M. Rouphail, J. E. Hummer, and J. S. Milazzo. 1998. Operational analysis of uninterrupted bicycle facilities. Transportation Research Record 1636: 29-36.

Aultman-Hall, L., and F. L. Hall. 1998. Ottawa-Carleton commuter cyclist on-and off-road incident rates. Accident Analysis and Prevention 30(1): 29-43.

Botma, H. 1995. Method to determine level of service for bicycle paths and pedestrian-bicycle paths. Transportation Research Record 1502: 38-44.

Broach, J., J. Dill, and J. Gliebe. 2012. Where do cyclists ride? A route choice model developed with revealed preference GPS data. Transportation Research A 46: 1730-1740.

CROW. 2007. Design Manual for Bicycle Traffic. The Netherlands: National Information and Technology Platform for Infrastructure, Traffic, Transport and Public Space.

Decreto Ministeriale. November 30 1999, n. 557. Regolamento recante norme per la definizione delle caratteristiche tecniche delle piste ciclabili.

European Economic and Social Committee. 2012. European Cycling Lexicon.EUR-OP. doi:10.2864/10239.

Green, J. S., J. E. Hummer, N. M. Rouphail. 2003. Using the number of passing and meeting events to design pedestrian and bicycle shared-use paths. Presented at the Second Urban Street Symposium: Uptown, Downtown, or Small Town: Designing Urban Streets that Work, July 28-30, 2003, Anaheim, CA.

Hood, J., E. Sall, and B. Charlton. 2011. A GPS-based bicycle route choice model for San Francisco, California. Transportation Letters 3(1): 63-75.

Krizek, K.J., and R. W. Roland. 2005. What is at the end of the road? Understanding discontinuities of on-street bicycle lane in urban settings. Transportation Research D 10: 55-68.

Larsen, J., and A. El-Geneidy. 2011. A travel behavior analysis of urban cycling facilities in Montreal, Canada. Transportation Research D 16: 172-177.

Lusk, A. C., P. G. Furth, P. Morency, L. F. Miranda-Moreno, W. C. Willet, and J. T. Dennerlein. 2011. Risk of injury for bicycling on cycle tracks versus in the street. Injury Prevention 17(2): 131-135.

Lusk, A. C., P. Morency, L. F. Miranda-Moreno, W. C. Willett, and J. T. Dennerlein. 2013. Bicycle guidelines and crash rates on cycle tracks in the United States. American Journal of Public Health 103(7): 1240-1248.

Lusk, A. C., X. Wen, and L. Zhou. 2014. Gender and used/preferred differences of bicycle routes, parking, intersection signals, and bicycle type: Professional middle class preferences in Hangzhou, China. Journal of Transport and Health 1(2): 124-133.

Menghini, G., N. Carrasco, N. Schüssler, and K. W. Axhausen. 2010. Route choice of cyclists in Zurich. Transportation Research A 44: 754-765.

NACTO. 2012. Urban Bikeway Design Guide. Washington, DC: National Association of City Transportation Officials.

Phillips, R. O., T. Bjørnskau, R. Hagman, and F. Sagberg. 2011. Reduction in car-bicycle conflict at a road-cycle path intersection: Evidence of road user adaptation? Transportation Research F 14: 87-95. Schepers, J. P., P. A. Kroeze, W. Sweers, and J. C. Wüst. 2011. Road factors and bicycle—motor vehicle 
crashes at unsignalized intersection. Accident Analysis and Prevention 42: 853-861.

Schweizer, J., and F. Rupi. 2014. Performance evaluation of extreme bicycle scenarios. Procedia of Social and Behavioral Sciences 111: 508-517.

Sener, I., N. Eluru, and C. Bhat. 2009. An analysis of bicycle route choice preferences in Texas, US. Transportation 36(5): 511-539.

Sorton, A., T. Walsh. 1994. Stress level as a tool to evaluate urban and suburban bicycle compatibility. Transportation Research Record 1438: 17-24.

Stinson, M. A., C. R. Bhat. 2003. An analysis of commuter bicyclist route choice using a stated preference survey. Transportation Research Record 1829: 107-115.

Strauss, J., L. F. Miranda-Moreno. 2013. Spatial modelling of bicycle activity at signalized intersections. Journal of Transport and Land Use 6(2): 47-58.

Tilahun, N., D. M. Levinson, J. K. Krizek. 2007. Trails, lanes, or traffic: The value of different bicycle facilities using an adaptive stated preference survey. Transportation Research A 41: 287-301.

Virkler, M., R. Balasubramanian. 1998. Flow characteristics on shared hiking- biking-jogging trails. Transportation Research Record 1636: 43-46.

Wilkinson, W., A. Clarke, B. Epperson, and R. Knoblauch. 1994. The Effects of Bicycle Accommodations on Bicycle/Motor Vehicle Safety and Traffic Operations. Washington, DC: U.S. Department of Transportation, Federal Highway Administration. 